\title{
A Simple Method for Comparing Fungal Biomass in Infected Plant Tissues
}

\author{
Michael Ayliffe, ${ }^{1}$ Sambasivam K. Periyannan, ${ }^{1}$ Angela Feechan, ${ }^{2}$ Ian Dry, ${ }^{2}$ Ulrike Schumann, ${ }^{1}$ \\ Ming-Bo Wang, ${ }^{1}$ Anthony Pryor, ${ }^{1}$ and Evans Lagudah' \\ ${ }^{1}$ CSIRO Plant Industry, Box 1600, Clunies Ross Street, Canberra, ACT, 2601, Australia; ${ }^{2}$ CSIRO Plant Industry, Box 350 , \\ Glen Osmond, SA, 5064, Australia
}

Submitted 17 December 2012. Accepted 7 February 2013.

\begin{abstract}
Plant phenotypes resistant and susceptible to fungal pathogens are usually scored using qualitative, subjective methods that are based upon disease symptoms or by an estimation of the amount of visible fungal growth. Given that plant resistance genes often confer partial resistance to fungal pathogens, a simple, sensitive, nonsubjective quantitative method for measuring pathogen growth would be highly advantageous. This report describes an in planta quantitative assay for fungal biomass based upon detection of chitin using wheat germ agglutinin conjugated to a fluorophore. Using this assay, the growth of wheat rust pathogens on wheat was assayed and the additivity of several adult plant and seedling resistance genes to Puccinia striiformis, $P$. graminis, and $P$. triticina was assayed on both glasshouseand field-grown material. The assay can discriminate between individual rust pustules on a leaf segment or, alternatively, compare fungal growth on field plots. The quantification of Erysiphe necator (powdery mildew) growth on Vitis vinifera (grapevine) is also demonstrated, with resistant and susceptible cultivars readily distinguished. Given that chitin is a major cell wall component of many plant fungal pathogens, this robust assay will enable simple and accurate measurement of biomass accumulation in many plant-fungus interactions.
\end{abstract}

Plant disease resistance to fungal pathogens is essential for the reliable production of food crops (Ayliffe et al. 2008; Fischer et al. 2012; Strange 2005). In many instances, resistance to fungal pathogens is not an unambiguous case of immunity versus susceptibility but, more often, is a quantitative difference in fungal growth between resistant, tolerant, and susceptible lines. Frequently, a disease score is estimated based upon visual observation of fungal infection sites (Gassner and Straib 1932; McNeal et al. 1971; Stakman et al. 1962) or, alternatively, by the progression of plant disease symptoms (Bani et al. 2012; Diener and Ausuble 2005; Horsfall and Barratt 1945; Lievens et al. 2006; Walker and Bosland 1999; Wilhem et al. 1974). Such subjective scoring systems are prone to error and require significant experience in plant pathology to be meaningful (Bock et al. 2010). Furthermore, both approaches can only be applied toward

Corresponding author: M. Ayliffe; Telephone: +1 6126246 5221; Fax: +1 6126246 5000; E-mail: Michael.ayliffe@ csiro.au

* The $\boldsymbol{e}$-Xtra logo stands for "electronic extra" and indicates three supplementary figures are published online.

(C) 2013 The American Phytopathological Society the end of the disease cycle and the latter can also be confounded by environmental factors that produce disease-like symptoms.

Therefore, a need exists for a simple and accurate method for the quantification of fungal disease progression on both field and laboratory material. A number of studies have attempted to address this problem. Plant disease progression has been quantified by the labor-intensive process of counting infection site numbers per leaf area or physically measuring infection site sizes, which has obvious sample size and throughput limitations (Ahn and Ou 1982; Delgado et al. 2002; Jafary et al. 2006; Pariaud et al. 2009). Alternatively, molecular biological techniques such as RNA- or DNA-based quantitative polymerase chain reaction (PCR) have been used for pathogen quantification (Hogg et al. 2007; Klosterman 2012; Larsen et al. 2007; Nicholson et al. 1998; Silvar et al. 2005). However, this approach requires nucleic acid extraction, enzyme amplification, and primer optimization. It also is prone to cross contamination, relatively labor intensive, and a technically demanding experimental undertaking for true quantitativity to be obtained. More recently, image-scanning methodologies have been used for quantification of disease symptoms, which often requires sophisticated instruments, is relatively low throughput, and is not feasible until symptoms become apparent (Goodwin and Hsiang 2010; Seiffert and Schweizer 2005; Wijekoon et al. 2008). Transgenic pathogens expressing reporter genes have also been used for biomass quantification (Bao et al. 2000; Chen et al. 2003; Kamoun et al. 1998; Papdopoulou et al. 2005); however, this approach is clearly not applicable to field situations and limited to transformable fungal pathogens. Other fungal pathogen quantification methods have used enzyme-linked immunosorbent assay assays (El-Nashaar et al. 1986; Harrison et al. 1990) or the pathogen conversion of a chromogenic substrate (Diener 2012). Although each of these approaches has been useful, they suffer from being either laborious, technically demanding, pathogen specific, not suitable for field studies, or only relatively low throughput.

Previously, we developed a method for microscopic resolution of fungal infection structures in infected plant leaves (Ayliffe et al. 2011). This method uses the lectin wheat germ agglutinin (WGA) conjugated to a fluorophore such as alexa488 or fluorescein isothiocyanate (FITC) for in planta visualization of fungal infection structures. WGA conjugates have been used extensively for resolution of fungal infection structures (Chong et al. 1985; Meyberg 1988) O'Connell and Ride 1990) due to the high binding specificity of WGA to chitin, a major cell wall component of many fungal species. WGA specifically binds to trimers of $\mathrm{N}$-acetylglucosamine and does not bind to the closely related cell wall component chitosan (Allen 
et al. 1973; Bhavanandan and Kaltic 1979; El Gueddari et al. 2002; Meyberg 1988; Roth 1978).

In this report, we have modified this histochemical assay to produce a method for quantification of in planta fungal biomass that is simple, sensitive, rapid, and reliable. The amount of tissue that can be processed is unlimited, allowing for large amounts of replicated material to be processed together, although as little as a $3-\mathrm{cm}$ wheat leaf segment is sufficient material for quantification. Prior to processing, the tissue can be stored for an extensive period of time and samples can also be viewed under high-resolution microscopy before quantification. This method uses readily available laboratory equipment and chemicals and is relatively inexpensive.

\section{RESULTS}

\section{Development of the WGA chitin assay.}

Previously, we have undertaken microscopy of fungal infected leaf tissue after clearing leaves by autoclaving in $1 \mathrm{M} \mathrm{KOH}$ and staining with WGA-FITC (Ayliffe et al. 2011). This simple procedure shows high specificity for fungal chitin, with little background staining observed. We have converted this procedure into a quantitative assay for chitin accumulation in fungalinfected plant tissue. Essentially, tissue is harvested, autoclaved

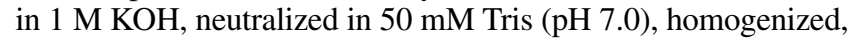
and stained with WGA-FITC; and samples are washed three times to remove unbound stain prior to quantifying fluorescence in a fluorometer (discussed below). We have named this method the WGA chitin (WAC) assay.

To determine whether the binding of WGA to chitin particles is quantitative, uninfected wheat (Triticum aestivum) leaf tissue homogenate was used to serially dilute a suspension of ground-up, purified chitin particles in triplicate reactions. A linear curve $\left(R^{2}=0.9832\right)$ with a directly proportional relationship was obtained when $0,5,10,20,30$, and $40 \mu \mathrm{g}$ of chitin particles were added to $40 \mathrm{mg}$ of leaf tissue homogenate (Fig. 1A). These data confirm the quantitative nature of WGA binding to chitin particles.

Given that a finite amount of WGA-FITC is available in each sample, it was of interest to determine the kinetics of chitin staining in this assay. A second standard curve was produced from uninfected wheat leaf homogenate that contained increasing amounts of chitin (Fig. 1B). A linear relationship was shown to exist between chitin content and fluorescence when up to $40 \mu \mathrm{g}$ of chitin was present in $40 \mathrm{mg}$ of plant tissue that was stained with $10 \mu \mathrm{g}$ of WGA-FITC. When more than $40 \mu \mathrm{g}$ of chitin was added, WGA-FITC appeared to become limiting, leading to a nonlinear relationship between fluorescence and chitin content. Therefore, in subsequent experiments, samples were further diluted and the assay repeated if fluorometric values exceeded 200,000 units (Fig. 1A and B). These diluted samples were then normalized by multiplying the observed fluorescence value by the dilution factor.

To confirm that the WAC assay is quantitative for the detection of fungal material in plant leaf tissue, leaves from 'Sonora' wheat that had been infected with Puccinia graminis f. sp. tritici were harvested 12 days postinoculation (dpi). Uninfected leaves from these plants were placed into one pool and heavily rustinfected leaves from the same plants were placed into a second pool. Both samples were then processed and triplicate samples produced that contained $40 \mathrm{mg}$ of uninfected homogenate combined with $0,400 \mu \mathrm{g}, 2 \mathrm{mg}, 4 \mathrm{mg}, 8 \mathrm{mg}$, or $16 \mathrm{mg}$ of rust-infected leaf homogenate. Samples were then stained with WGAFITC, washed, and subjected to fluorometry. From this serial dilution experiment, a directly proportional, linear relationship was observed $\left(R^{2}=0.977\right)$ between the amount of $P$. graminis $\mathrm{f}$. sp. tritici-infected leaf homogenate and fluorescence (Fig. 1C).
To further investigate these homogenates, samples were centrifuged onto the surface of a mini-column membrane and observed by fluorescence microscopy, where an increasing amount of fluorescence was present that correlated with increasing amounts of rust-infected leaf material being present (Fig. 2A). Higher magnification microscopy confirmed that the WGAFITC stained material present in these homogenates was of fungal origin, with little background observed from plant tissue (Fig. 2B to E).

An additional consideration is that treatment of chitin with high temperatures and alkaline solutions leads to chitin dea-

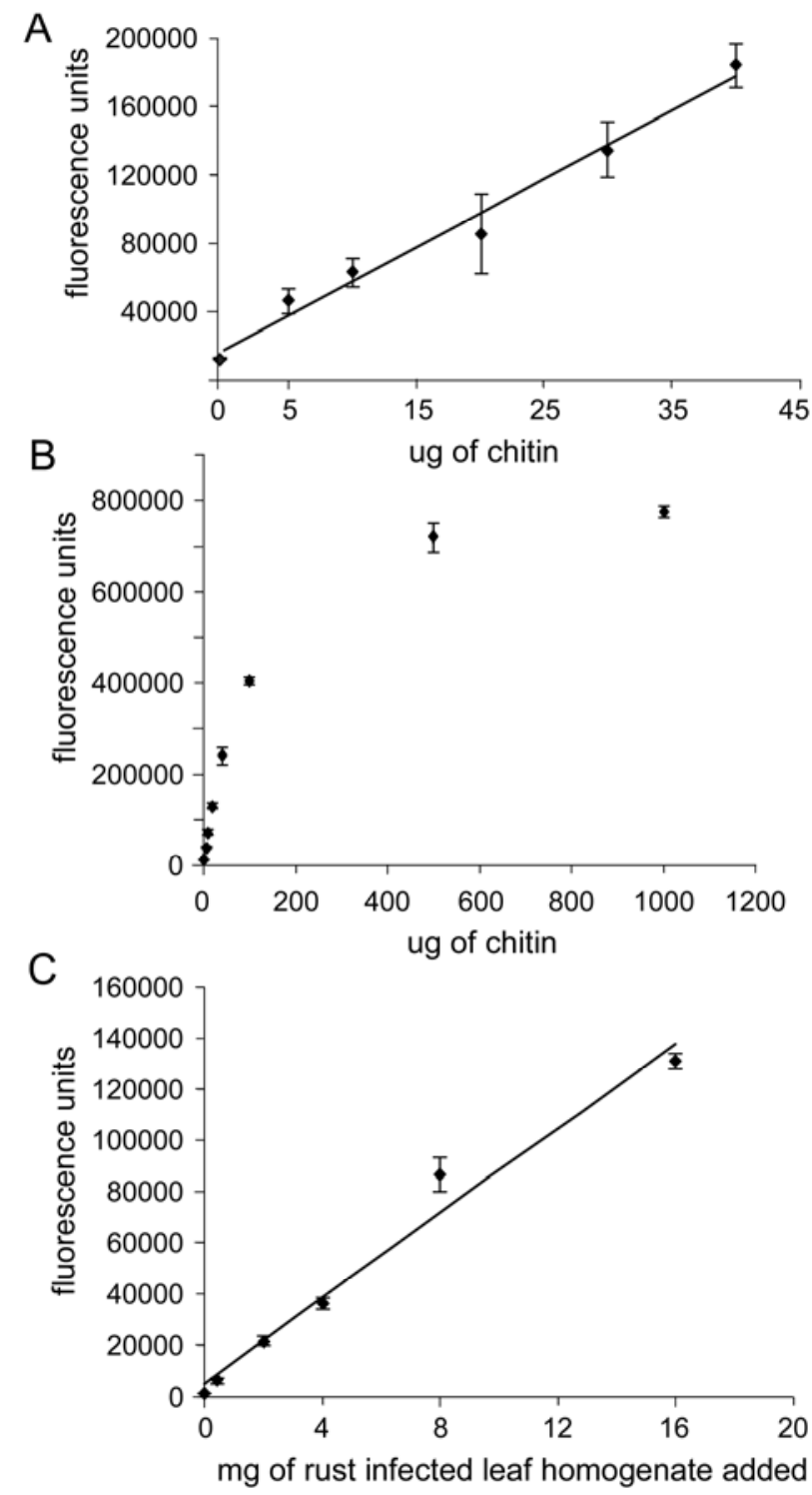

Fig. 1. Quantitative nature of the wheat germ agglutinin (WGA) chitin (WAC) assay. A, A chitin standard curve generated by the WAC assay. The amount of chitin suspension added to uninfected wheat leaf homogenate is shown on the $x$ axis and fluorescence shown on the $y$ axis. Each point is the average of four technical replicates. B, WGA-fluorescein isothiocyanate becomes limiting with increasing chitin concentration. The amount of chitin suspension added to uninfected plant tissue is shown on the $x$ axis and fluorescence shown on the $y$ axis. The relationship between chitin content and fluorescence is no longer directly proportional with increasing chitin concentration. Each point is the average of four replicate samples. C, A directly proportional relationship is seen between rust-infected tissue amount and fluorescence. Homogenate from rust-infected leaf tissue was added to uninfected leaf tissue and processed via the WAC assay. The amount of rust-infected leaf tissue present in each sample is indicated on the $x$ axis while fluorescence is shown on the $y$ axis. Triplicate reactions were undertaken for each sample point. Standard error bars are indicated for each sample. 
cetylation to chitosan (No and Meyers 1995). This process is used in industry to produce chitosan from the chitin shells of crustaceans, where concentrated potassium or sodium hydroxide solutions (30 to 50\%) are used in conjunction with high temperatures $\left(60\right.$ to $150^{\circ} \mathrm{C}$ ) (Hisamatsu and Yamada 1989; No and Meyers 1995). Because the WAC assay uses autoclaving of infected plant tissue in $1 \mathrm{M} \mathrm{KOH}(5.6 \%)$ to remove chlorophyll and aid in tissue maceration, it was of interest to determine whether this process is, first, necessary and, second, likely to result in substantial chitin deacetylation of fungal material because WGA does not bind chitosan.

P. graminis f. $\mathrm{sp}$. tritici spores $(200 \mathrm{mg})$ were germinated on the surface of water and the resultant germ tubes and spores collected and homogenized by grinding. Three aliquots of this sample were resuspended in $50 \mathrm{mM}$ Tris $(\mathrm{pH} \mathrm{7.0)}$, three were autoclaved in $50 \mathrm{mM}$ Tris $(\mathrm{pH} \mathrm{7.0)}$, and three were autoclaved in 1 $\mathrm{M} \mathrm{KOH}$ followed by neutralization in $50 \mathrm{mM}$ (Tris $\mathrm{pH} \mathrm{7.0)}$ ). All samples were resuspended in $3 \mathrm{ml}$ of $50 \mathrm{mM}$ Tris, $\mathrm{pH} 7.0$, and four replicates of $30 \mu \mathrm{l}$ were measured via the WAC assay for each of the nine samples. A small (19\%) increase in WGA staining was observed when samples were autoclaved in Tris $(\mathrm{pH}$ 7.0) compared with unautoclaved samples ( $t$ test, $P=0.015$, based on comparing the average of all three samples from each group). However, a threefold increase was apparent when sam- ples were autoclaved in $1 \mathrm{M} \mathrm{KOH}$ (Fig. 3A). This dramatic increase in WGA staining is likely to reflect much greater stain accessibility following combined $\mathrm{KOH}$ and autoclaving treatments and confirms the importance of this step.

To determine whether substantial chitin deacetylation is occurring during autoclaving in $1 \mathrm{M} \mathrm{KOH}$, a sample of a 1-mg/ml suspension of chitin particles in $50 \mathrm{mM}$ Tris, $\mathrm{pH} 7.0$, was divided in half; one-half was autoclaved in $1 \mathrm{M} \mathrm{KOH}$ and then neutralized in $50 \mathrm{mM}$ Tris, $\mathrm{pH} 7.0$, while the remainder remained untreated. Aliquots $(0,20,40$, and $60 \mu \mathrm{l})$ of each sample were stained via the WAC assay with uninfected wheat tissue homogenate added to each sample as a carrier. Rather than decreased staining in the $\mathrm{KOH} /$ autoclaved sample, a twofold increase in chitin staining was observed ( $t$ test, $P<0.05$ in all cases) (Fig. 3B). This was likely due to further fragmentation of the chitin particles during autoclaving providing a greater surface area of exposed chitin. Therefore, no evidence of substantial chitin deacetylation was observed.

\section{Application of the WAC method to wheat stem rust infection.}

Having demonstrated the quantitative nature of the WAC assay, the accumulation of $P$. graminis f. sp. tritici biomass during a fully compatible infection was examined. Sonora wheat
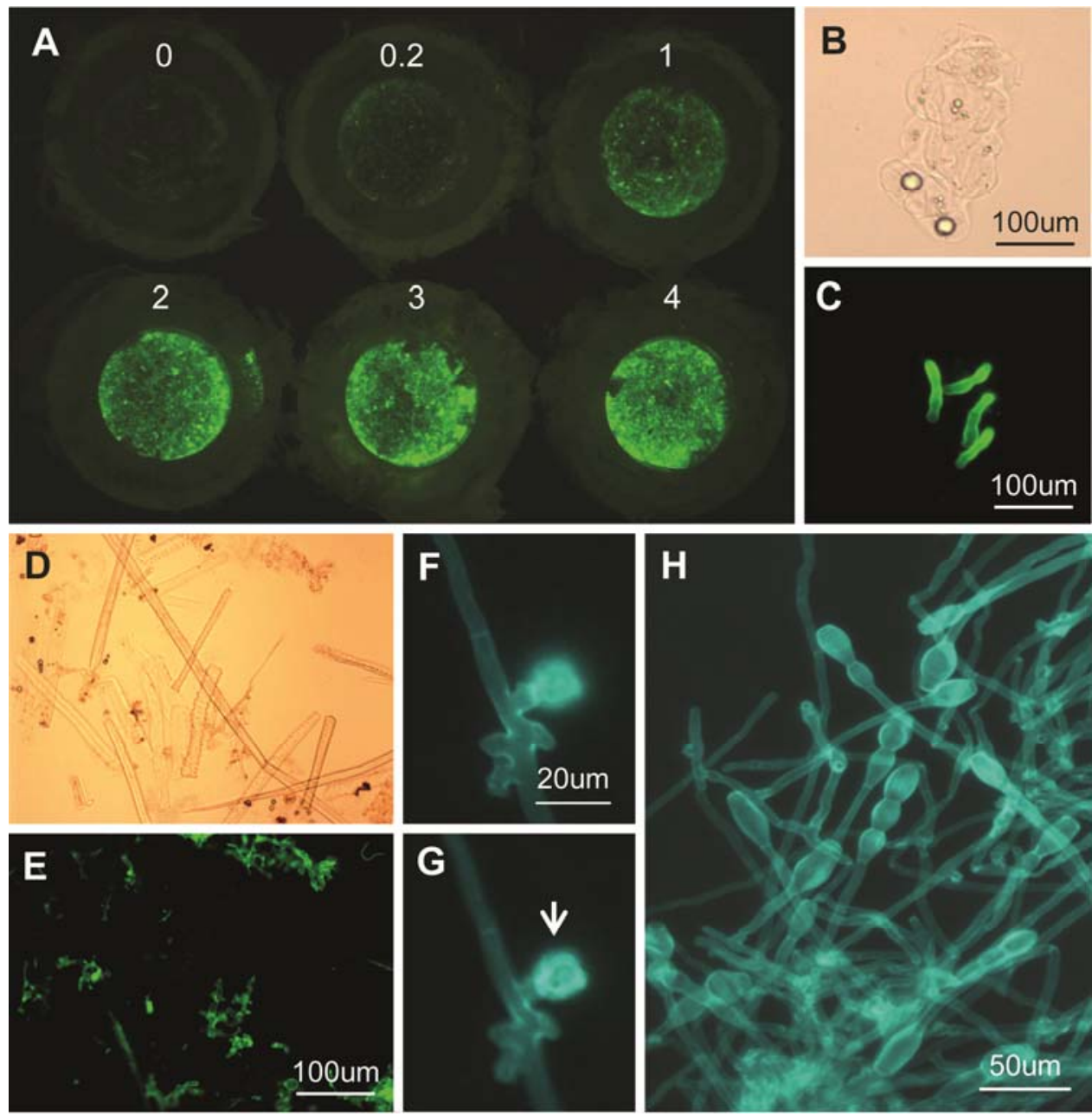

Fig. 2. Microscopic analysis of the wheat germ agglutinin (WGA) chitin (WAC) assay. A, Fluorescent microscopy of WAC assay samples centrifuged onto the surface of a minicolumn membrane. Each sample contained uninfected wheat tissue homogenate with Puccinia graminis f. sp. tritici-infected wheat tissue homogenate added. The number above each membrane indicates the quantity of rust-infected tissue homogenate (milligrams) added to each sample. B to $\mathbf{E}$, Bright-field microscopy of leaf tissue homogenate from P. graminis f. sp. tritici-infected wheat tissue $\mathbf{B}$ and $\mathbf{D}$, after WAC assay treatment; $\mathbf{C}$ and $\mathbf{E}$, the same samples showing WGA-fluorescein isothiocyanate (FITC) staining, respectively. F to H, WGA-FITC staining of Erysiphe necator growing on Vitis vinifera 'Cabernet Sauvignon' leaf tissue with F, extracellular hyphae; G, intracellular haustorium (arrow); and $\mathbf{H}$, conidiophores apparent. F and G are different focal planes of the same sample. 
was infected with $P$. graminis f. sp. tritici and leaf samples harvested at 24-h intervals. An exponential increase in chitin accumulation was observed, with a fourfold increase in fluorescence in infected plants relative to control plants at 4 dpi ( $t$ test, $P=4 \mathrm{E}^{-05}$ ) which increased to a 40 -fold difference by 11 dpi (Fig. 4A).

To examine the minimum sensitivity of the WAC assay, wheat leaf tissue heavily infected with $P$. graminis f. sp. tritici was cut into four $1.5-\mathrm{cm}$ segments, such that each segment contained 100 pustules approximately 0.5 to $1 \mathrm{~mm}$ in length. Each segment was homogenized and the homogenate added to
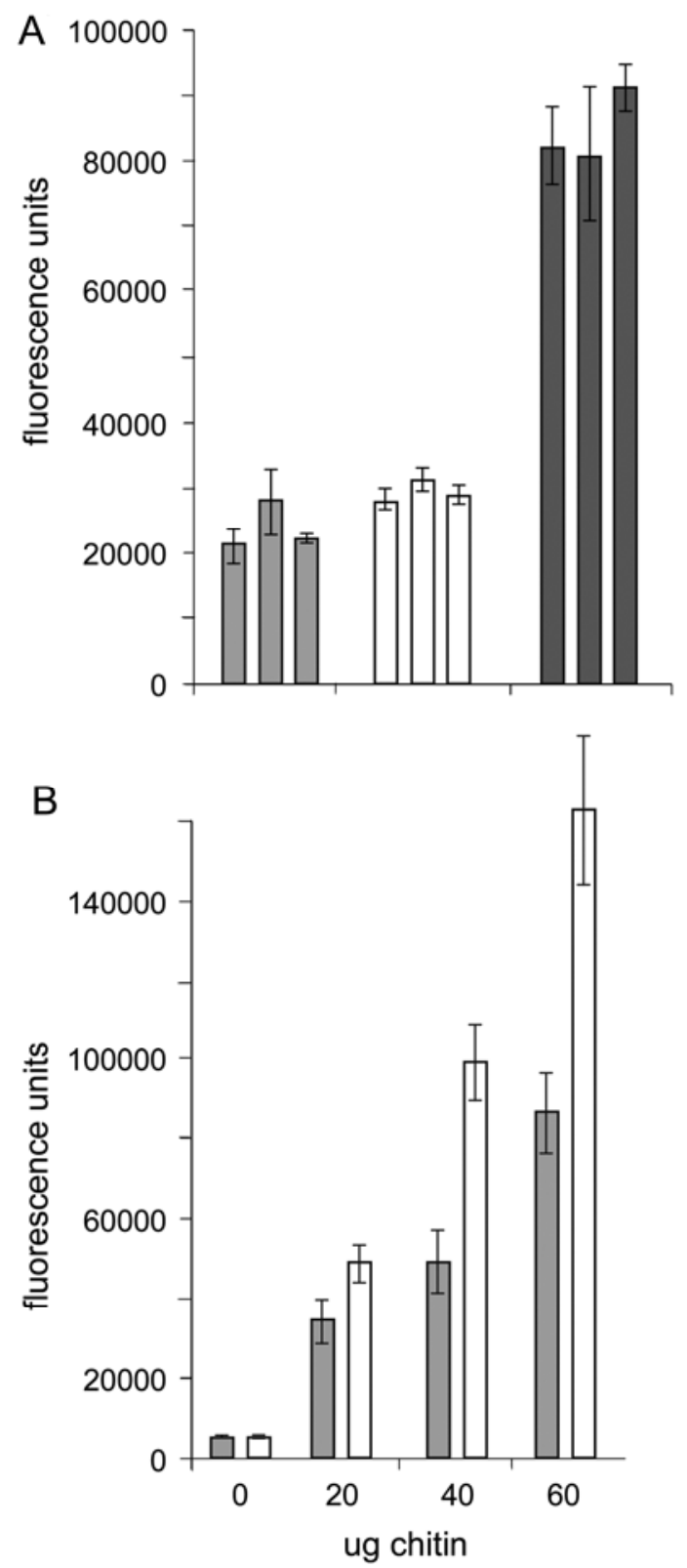

Fig. 3. Effect of autoclaving and $\mathrm{KOH}$ treatment on the wheat germ agglutinin chitin assay. A, Homogenate of germinated Puccinia graminis f. sp. tritici uredospores was either untreated (gray columns), autoclaved (white columns), or resuspended in $1 \mathrm{M} \mathrm{KOH}$, autoclaved, and then neutralized (black columns). Triplicate samples were measured for each treatment. Each column represents the average fluorescence obtained from four replicate samples. B, A $1-\mathrm{mg} / \mathrm{ml}$ suspension of chitin particles in $50 \mathrm{mM}$ Tris was either left untreated (gray columns) or autoclaved in $1 \mathrm{M} \mathrm{KOH}$ and then neutralized in $50 \mathrm{mM}$ Tris, $\mathrm{pH} 7.0$ (white columns). Aliquots $(0,20$, 40 , or $60 \mu 1$ ) of each sample were then added to homogenized, uninfected wheat leaf tissue and quantified. Each column represents the average value of six technical replicates.
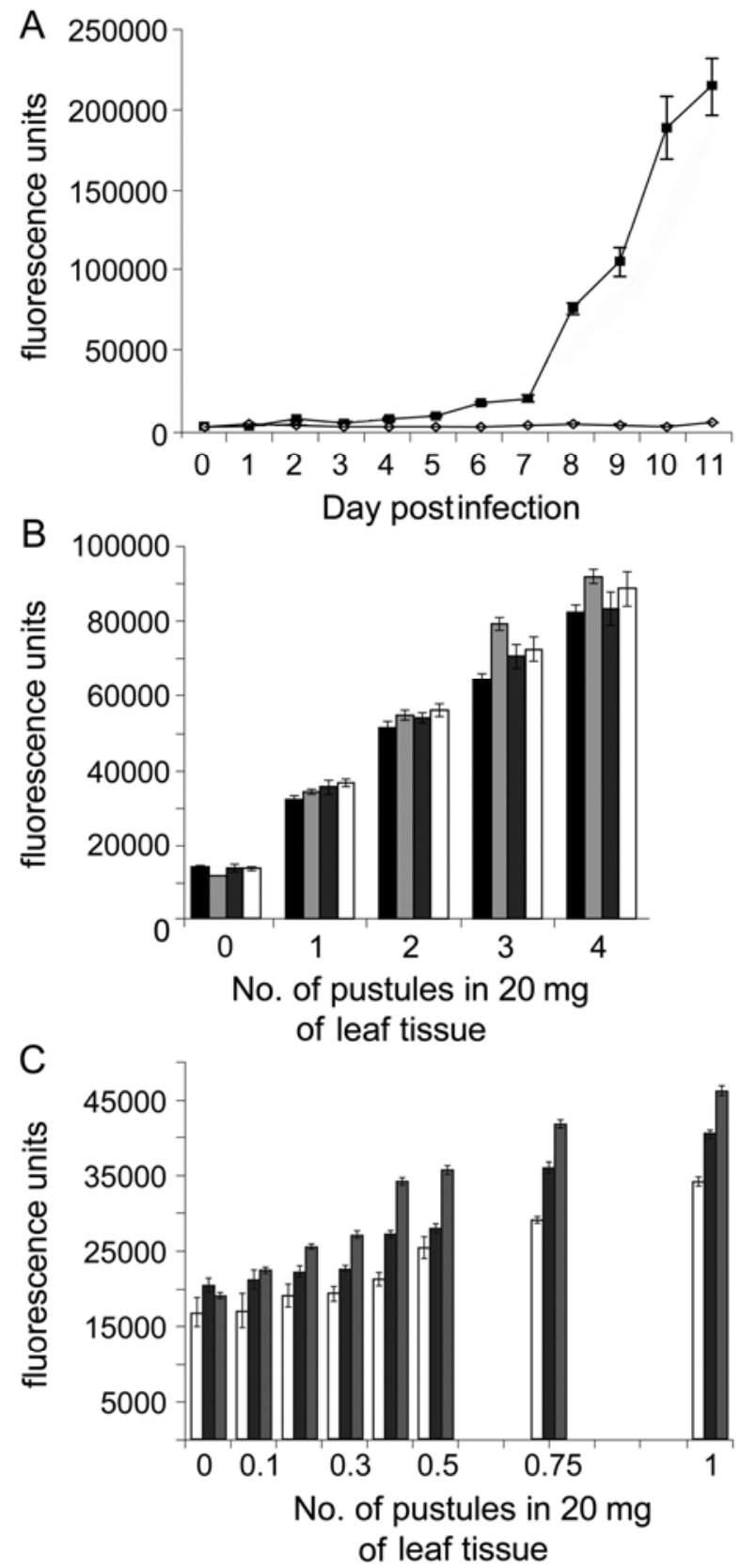

Fig. 4. In planta quantification of Puccinia graminis f. sp. tritici growth on wheat. A, Quantification of P. graminis f. sp. tritici growth on 'Sonora' wheat by the wheat germ agglutinin chitin (WAC) assay. Fluorescence values from rust-infected seedling homogenates are shown as black squares while those from uninfected control seedlings are shown as unshaded diamonds. In all, 10 pots were infected with $P$. graminis f. sp. tritici while 10 equivalent pots were uninfected. Each time point was produced by harvesting all of the leaves from a single seedling from each pot and then pooling tissue from all 10 seedlings. Each pooled sample was homogenized and resuspended at $200 \mathrm{mg} / \mathrm{ml}$. Each value was obtained from six technical replicates of a single pooled tissue sample. Standard errors are indicated. B, Minimum detection level of $P$. graminis $\mathrm{f}$. sp. tritici infection of wheat by the WAC assay. Four rust-infected wheat leaf homogenates were diluted with uninfected leaf homogenate to generate $0,1,2,3$, and 4 pustule equivalents per $20 \mathrm{mg}$ of tissue. Each column represents the average of six technical replicates with columns that are the same color containing tissue from the same rust-infected homogenate. C, Further analysis of the minimum detection of the WAC assay. Three homogenates, each containing $150 \mathrm{P}$. graminis f. sp. tritici pustules, were serially diluted with uninfected leaf homogenate to generate $0,0.1,0.2,0.3,0.4,0.5,0.75$, and 1 pustule equivalent per $20 \mathrm{mg}$ of tissue. White and black columns are the average fluorescence values obtained from 6 technical replicates, while gray columns are the average of 24 technical replicates. Columns of the same color are derived from the same tissue sample. 
$20 \mathrm{mg}$ of uninfected wheat leaf homogenate to equal $0,1,2,3$, and 4 rust pustules equivalents, respectively. WAC analysis indicated that a single pustule equivalent showed a threefold higher fluorescence than $20 \mathrm{mg}$ of uninfected tissue (Fig. 4B). In addition, a statistically significant $(t$ test, $P<0.05)$ difference in chitin content was apparent between all samples containing different amounts of homogenate, demonstrating that a single pustule difference can be readily discriminated on a 1.5 $\mathrm{cm}$ segment of wheat leaf tissue.
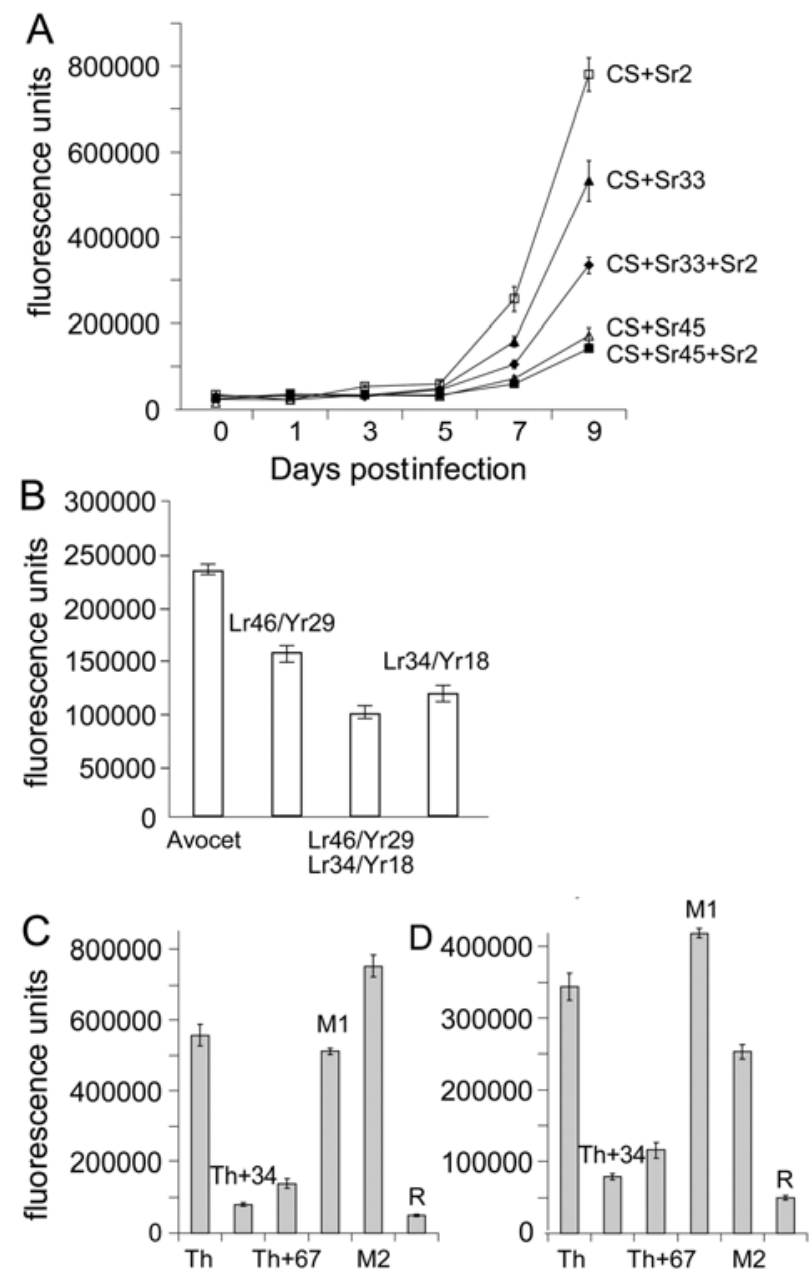

Fig. 5. Quantification of rust growth in resistant and susceptible lines. A, Chitin quantification of Puccinia graminis f. sp. tritici growth on 'Chinese Spring' (CS) wheat lines containing either Sr2, Sr33, Sr45, Sr2 + Sr33, or $S r 2+S r 45$. Twenty seedlings from each line were planted in each of five pots. At each time point, two seedlings from each pot were harvested and seedlings of the same line pooled (i.e., 10 pooled seedlings per time point per genotype). Each pooled sample was homogenized and tissue was resuspended at $200 \mathrm{mg} / \mathrm{ml}$. Each time point is the average of six technical replicates that each contained $20 \mathrm{mg}$ of the pooled tissue sample. B, 'Avocet' and F2 lines homozygous for either Lr46/Yr29, Lr34/Yr18, or both genes were grown in field plots and naturally infected with $P$. striiformis $\mathrm{f}$. sp. tritici and $P$. triticina. Five flag leaves were harvested from each F2 line and leaves from 10 separate F2 lines were pooled for each genotype. Chitin quantification was undertaken on each pooled leaf homogenate with six technical replicates per sample. $\mathbf{C}$ and $\mathbf{D}$, Quantification of rust infection of Thatcher (Th), Thatcher containing Lr34/Yr18 (Th+34), or Thatcher containing Lr67/Yr46 (Th+67). Lines M1 and M2 were susceptible ethylmethane sulphonate mutants of $\mathrm{Th}+67$ while line $\mathrm{R}$ was a resistant sib. Plants were infected under natural field conditions with $P$. striiformis f. sp. tritici and $P$. triticina. Each column is the average fluorescence of six technical replicates from a pooled leaf tissue sample. Each pooled sample contained five flag leaves randomly harvested from each genotype. Data presented in $\mathrm{C}$ is based upon equivalent mass of homogenate while the data in $\mathrm{D}$ is based upon an equivalent number of flag leaves homogenized in the same buffer volume.
To further resolve the detection limit of the WAC assay, the experiment was repeated, except that three leaf segments, each containing $150 P$. graminis $\mathrm{f}$. sp. tritici pustules, were processed and added to uninfected leaf tissue to produce $0.1,0.2,0.3,0.4$, $0.5,0.75$, and 1 pustule equivalents in $20 \mathrm{mg}$ of uninfected tissue. These tissue ratios are equivalent to $1,2,3,4,5,7.5$, and 10 pustules on a $15-\mathrm{cm}$ wheat leaf because a $15-\mathrm{cm}$ leaf weighs 200 $\mathrm{mg}$. Chitin from the first two leaf segments was measured using 6 replicates per sample while, for the third segment, 24 replicates were used. An increasing amount of fluorescence was detected in sequential samples that corresponded to an increasing amount of rust homogenate (Fig. 4C). Each experiment produced a straight line with a similar gradient. The consistent difference in chitin values between the same pustule equivalents is likely to reflect natural variation in the biomass of the 150 rust pustules present on each leaf segment.

For samples in which six replicates were performed, a significant difference in chitin content $(t$ test, $P<0.05)$ was obtained only between samples that varied by at least 0.25 pustule equivalents. In contrast, when 24 replicates were undertaken on each sample from the third leaf segment, all samples contained significantly different chitin amounts $(t$ test, $P<0.05)$. This latter data indicates that the WAC assay can distinguish between single pustules on a $15-\mathrm{cm}$ leaf when highly replicated; however, from a practical viewpoint, the minimum resolution is a difference of approximately three pustules on a $15-\mathrm{cm}$ wheat leaf.

An additional consideration when dealing with fungal pathogens is the loss of chitin biomass as a consequence of spore dispersal or spore loss during harvesting. To determine the contribution of spore biomass to total chitin content, tubes were placed over each of five wheat leaves densely infected with $P$. graminis f. sp. tritici sporulating pustules. Leaves were then autoclaved in $1 \mathrm{M} \mathrm{KOH}$ and the intact leaf removed from the solution to leave behind a $P$. graminis $\mathrm{f}$. sp. tritici spore suspension. (The autoclaving process causes greater spore shedding than does vigorous shaking). Each leaf and spore suspension was then processed, with centrifugation used at all steps to prevent spore loss during buffer changes. From these five leaves, $97 \%$ or greater WGA-FITC staining occurred in the leaf homogenate relative to the spore homogenate (Supplementary Fig. S1). Therefore, loss of $P$. graminis f. sp. tritici spores from infected wheat leaves during harvesting has a minor effect on total fluorescence of infected leaf homogenates.

Assaying the additive effects of wheat rust resistance genes.

Many wheat stem rust resistance genes provide partial resistances that are challenging to score qualitatively. To examine the WAC assay in this context, the additivity of resistance conferred by the $S r 2$ resistance gene with either $S r 33$ or $S r 45$ was assayed in 'Chinese Spring' (CS) wheat seedlings. Each of these genes confers partial resistance to $P$. graminis f. sp. tritici; however, $\mathrm{Sr} 2$ can only be detected as an adult plant resistance, whereas $\mathrm{Sr} 45$ is known to provide the most effective resistance of these three genes. Glasshouse-grown seedlings were infected with $P$. graminis $\mathrm{f}$. $\mathrm{sp}$. tritici and chitin accumulation assayed over a time course (Fig. 5A). At 9 dpi, Sr33 caused a 32\% reduction in fungal growth compared with $\mathrm{Sr} 2$. However, when both genes were combined, a 57\% reduction in fungal growth was observed relative to $\mathrm{Sr} 2$ alone. In contrast, the more effective $\mathrm{Sr} 45$ gene resulted in a $78 \%$ reduction in fungal growth relative to $\mathrm{Sr} 2$. No significant difference in rust growth was observed between $\mathrm{Sr} 45$ lines and plants containing both $\mathrm{Sr} 45$ and $\operatorname{Sr} 2$ ( $t$ test, $P=0.17$ ).

The WAC assay was then tested for its ability to discriminate among field samples, where conditions are often more variable. The additivity of two partial, adult plant rust resistant genes, $L r 46 / Y r 29$ and $L r 34 / Y r 18$, which both confer resistance to $P$. triticina and $P$. striiformis f. sp. tritici, was tested in the field. 
These genes were each introduced into an 'Avocet' background and 10 homozygous $\mathrm{F} 2$ lines were identified that carried either Lr46/Yr29, Lr34/Yr18, both genes, or neither gene (designated as the Avocet genotype). Fifty seeds from each line were planted in randomized plots and naturally infected by adjacent spreader rows of susceptible wheat plants inoculated with $P$. striiformis $\mathrm{f}$. sp. tritici and $P$. triticina, as described below. Rust-infected flag leaf tissue from Avocet and derivative lines was harvested just after grain filling.

Five flag leaves from each line were processed by the WAC assay. The results from each genotype (i.e., 10 homozygous lines per genotype $\times 5$ flag leaves each) were pooled to obtain a final chitin biomass value. Compared with Avocet, chitin biomass accumulation was reduced by $34 \%$ due to $L r 46 / Y r 29$, $49 \%$ by $L r 34 / Y r 18$, and $57 \%$ when both genes were present (Fig. 5B). All pairwise $t$ test comparisons of these four data sets were significantly different $(P<0.05)$, except for the comparison between $\operatorname{Lr} 34 / \mathrm{Yr} 18$ plants and plants containing both genes $(P=0.074)$. Therefore, a substantial additive effect of Lr34/Yrl8 and Lr46/Yr29 was not observed in this experiment, consistent with previous reports (Lillemo et al. 2011).

A second field experiment was undertaken with similar natural infection conditions to compare the relative efficacy of Lr34/Yr18 with Lr67/Yr46 in the genetic background of 'Thatcher' wheat. From this analysis, $\operatorname{Lr34/Yr18}$ was shown to be more efficient at preventing rust growth than $L r 67 / Y r 46$, with an $86 \%$ reduction in fungal growth compared with Thatcher by the former gene and $75 \%$ reduction in growth by the latter gene (Fig. 5C). Significantly more rust growth (43\%) occurred on $L r 67 / Y r 46$ plants compared with $L r 34 / Y r 18$ plants ( $t$ test, $P=0.013$ ). Also included in this experiment were three M3 lines derived from an ethylmethane sulphonate (EMS) mutagenized Thatcher $L r 67 / Y r 46$ population. Two lines (M1 and M2) were independent mutants that had lost Lr67/Yr46 resistance (Fig. 5C) whereas the third line (R) maintained resistance (Fig. 5C). Similar amounts of chitin accumulation were observed between M1, M2, and Thatcher compared with Thatcher $L 67 / Y r 46$ and line R, further confirming the authenticity of these mutation events.

Statistical analysis indicated that all samples had significantly different amounts of chitin $(t$ test, $P<0.05)$. This is of relevance given that the Thatcher genotype and the M1 and M2 lines would be expected to have the same level of growth, as would Thatcher $\operatorname{Lr} 34 / \mathrm{Yr} 18$ and line R. The difference in chitin accumulation between members within each genetic group is presumably due to variation in rust inoculation under natural conditions. This point is further expanded upon below.

In this field experiment, five flag leaves were harvested from each plot, were pooled for WAC assay analysis, and were homogenized in $20 \mathrm{ml}$ of buffer. Because the number of flag leaves in each sample was identical, the data were measured in two ways: either by chitin amount present in $20 \mathrm{mg}$ of tissue (Fig. 5C), as per usual, or by chitin amount per milliliter of homogenate (Fig. 5D). This latter approach simplifies the assay because tissue does not need to be weighed and resuspended at an appropriate concentration but is dependent upon all flag leaves being similar in size. A comparison of Figure 5C and D shows that the technically more correct first method shows a similar although not identical graph to the second method. Therefore, although it is feasible to use the WAC assay based upon plant or organ number, a reduction in quantitative accuracy is apparent. Presumably, increased sample sizes would further reduce the discrepancy between these methods.

Comparative estimates of infection site sizes by WAC assay.

A feature of interest in plant pathology is the relative development of individual infection sites present on resistant and susceptible plants. This can be assessed by physically measuring a large number of infection sites, either macroscopically (Delgado et al. 2002; Pariaud et al. 2009) or microscopically (Ayliffe et al. 2011). However, both methods are laborious and, consequently, usually limited to smaller samples. To determine whether the WAC assay can provide an accurate quantification of average infection site biomass, $P$. graminis f. sp. triticiinfected leaves were harvested from CS wheat plants and derivatives containing either $\mathrm{Sr} 33$ or $\mathrm{Sr} 45$ at 5 and 7 dpi. Each sample consisted of a 3-cm rust-infected leaf section, with triplicate samples taken from plants of each genotype.

Leaf sections were stained with WGA-FITC and the total number of infection sites on each segment counted microscopically. A representative number of infection sites from each leaf were individually photographed and measured using the program Analysis. Total leaf fluorescence was then determined for each leaf segment using the WAC assay. A comparison between the average infection site size measured microscopically and average infection site biomass determined by dividing the total leaf fluorescence by the total number of infection sites is shown in Figure 6. A similar relationship was observed between measurements at both 5 and 7 dpi, demonstrating the validity of using the WAC assay for determining average relative infection site size. The WAC assay was significantly faster and less laborious for this analysis.

It is noteworthy that the average size and biomass of $P$. graminis f. sp. tritici pustules on CS leaves at 7 dpi were actually smaller than those observed on CS containing Sr33. This was due to the infection density being greater on the CS leaf segments used in this analysis compared with $\mathrm{CS}+\mathrm{Sr} 33$ tissue (Fig. 6B, compare numbers above gray columns). After $7 \mathrm{dpi}$, the infection sites on CS had essentially colonized the entire leaf and were unable to further develop. Therefore, although this infected CS tissue was suboptimal for comparative purposes between genotypes, this sample still robustly confirms the relationship between average infection site area and average fluorescence per infection site.

\section{Application of the WAC assay to other pathosystems.}

To demonstrate the application of the WAC method to other pathosystems, Vitis vinifera (grapevine) leaves were infected with Erysiphe necator (syn. Uncinula necator) (grapevine powdery mildew) and disease progression followed using the WAC assay. Microscopic analysis of mildew-infected grapevine leaves confirmed WGA-FITC staining of mildew infection structures (Fig. 2F through H). Subsequent microscopy of grapevine leaf homogenates indicated that, unlike rust-infected wheat tissue, a substantial proportion of fungal material was no longer associated with plant tissue (not shown). This appeared to be due to extracellular hyphae breaking off the leaf surface during processing, resulting in only haustoria remaining within plant epidermal cells (not shown). This difference between rust- and mildew-infected plant homogenates reflects the predominantly extracellular growth of mildew pathogens on the leaf surface while a majority of rust growth occurs within the leaf apoplast.

This separation of mildew hyphae from leaf tissue raised the possibility that fungal material could be lost during the neutralization step, where centrifugation was not usually employed during buffer changes. Therefore, centrifugation was used during all steps of the WAC process when using mildew pathogens. A time course of powdery mildew infection was undertaken on the susceptible $V$. vinifera cultivar (Cabernet Sauvignon) and a 10-fold increase in fluorescence was observed over the course of the infection (Fig. 7). When powdery mildew growth on the resistant grape genotype BC5:3294-R23 (which contains the resistance to $U$. necator $1[R U N 1]$ powdery mildew resistance gene) (Donald et al. 2002) was compared with the susceptible Cabernet Sauvi- 
gnon, a clear difference in fluorescence accumulation was apparent (Fig. 7). Hence, the WAC assay can also be used to successfully follow the infection of a woody dicotlyledonous plant species by an Ascomycete mildew pathogen. Similar analyses suggest that the WAC assay is also applicable to the interaction between wheat and Blumeria graminis f. sp. tritici (wheat powdery mildew) (Supplementary Fig. S2).

In contrast, attempts to quantify both Fusarium oxysporum and E. cichoracearum growth on Arabidopsis thaliana were complicated by WGA-FITC background staining of plant tissue (Supplementary Fig. S3). Background staining appeared to be related to tissue age and, hence, may be potentially overcome by ensuring that uninfected control tissue of exactly the
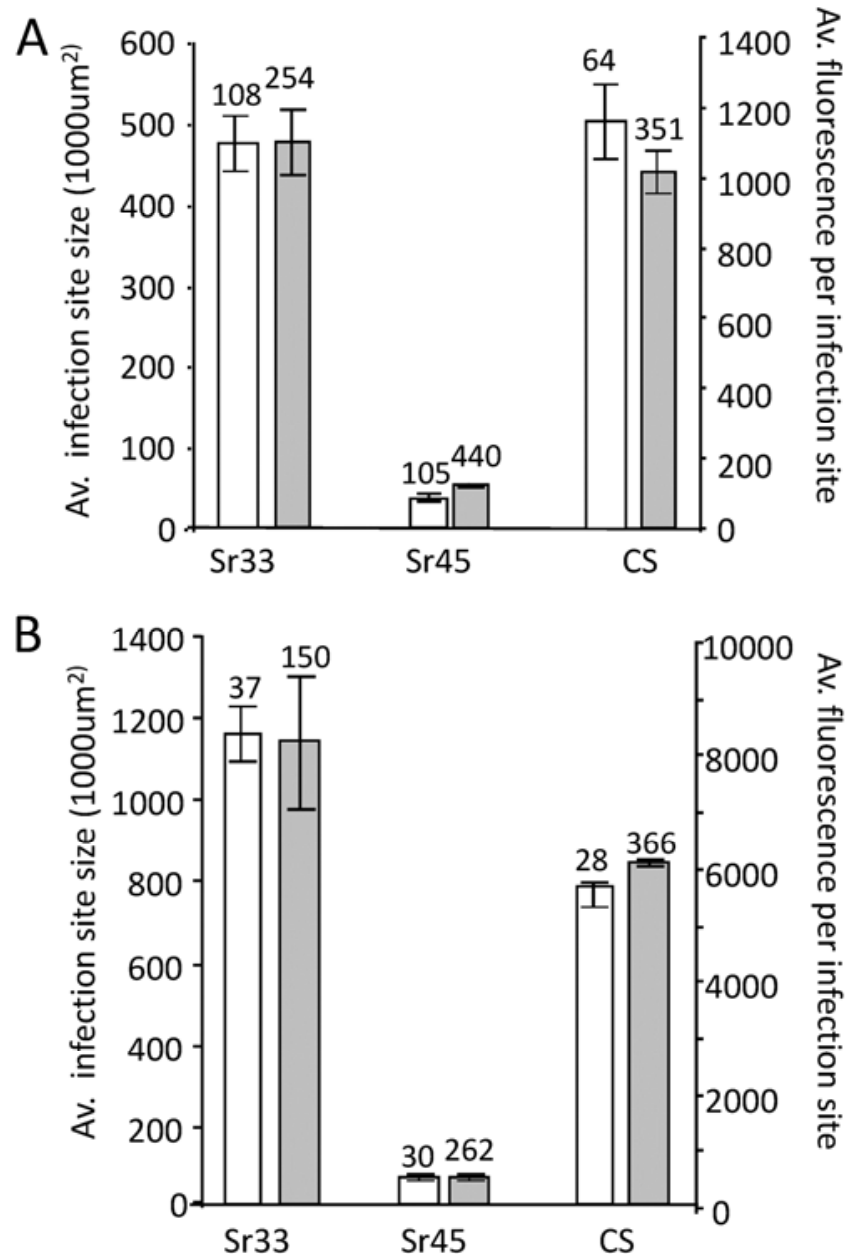

Fig. 6. Chitin quantification for determining average infection site size. Leaf samples (3-cm segments) from Puccinia graminis f. sp. tritici-infected seedlings were stained with wheat germ agglutinin (WGA)-fluorescein isothiocyanate. From each leaf segment, a representative number of infection sites were individually photographed microscopically and the infection site area was calculated for each pustule by measuring the image. An average infection site area was then calculated for each plant genotype, with each white column representing the average infection site area (left hand $y$ axis). The number of infection sites photographed and measured for each genotype is shown above each white column. In addition, the total number of infections sites on the same leaf segments used above was counted microscopically (numbers above gray columns). Leaf segments derived from the same cultivar were then pooled and the total chitin content measured by the WGA chitin assay. The average chitin content of an individual infection site was then calculated by dividing the total chitin fluorescence by the total number of pustules present on the pooled leaf segments. Each gray column represents the average fluorescence of an infection site on each genotype and is depicted relative to the $y$ axis on the right-hand side of the figure. $\mathbf{A}$, Samples were derived from 'Chinese Spring' (CS) or CS containing either Sr33 or Sr45, 5 days postinoculation (dpi) with P. graminis f. sp. tritici. B, Samples were harvested from the same pots $7 \mathrm{dpi}$. same developmental stage is included. This additional complication, however, makes this assay far less attractive for this species, although WGA conjugated to an alternative fluorophore could potentially be used to overcome this limitation.

\section{DISCUSSION}

This study reports a simple method for the rapid and reproducible quantification of in planta fungal biomass in both field- and glasshouse grown material. The technical advantages of this method include the fact that it is simple and provides a directly proportional relationship between fungal biomass and fluorescence. After autoclaving, samples can be stored indefinitely and transferred between laboratories without risk of pathogen spread. The protocol can be stopped at virtually any point in the procedure after autoclaving and large amounts of tissue can be pooled for processing, which enables samples from replicated trials to be pooled into a single representative sample. The method is relatively inexpensive, with approximately $\$ 0.38$ worth of WGA-FITC (Sigma Aldrich, St. Louis) used per sample (compared with $>\$ 0.50$ for $1 \mathrm{U}$ of Taq polymerase) and no additional expense or labor required for nucleic acid extraction or gel electrophoresis.

The scientific advantage of this method is that accurate, unbiased quantification provides a degree of scientific rigor that is not achieved by qualitative scoring. In addition, it is a true measure of pathogen growth rather than an inferred estimate based upon disease symptoms. Unlike qualitative disease scoring systems, the WAC assay enables the percent difference in fungal biomass to be determined between different samples, which is a biologically more meaningful value than a relative estimate. This is particularly useful when comparing the additivity of partial resistance genes, where a percent reduction in pathogen growth can be accurately determined, as we have demonstrated for wheat rust resistance genes. The output of the WAC assay is also readily amenable to statistical analyses, a process not commonly applied to qualitative scoring systems such as the Stakman scale.

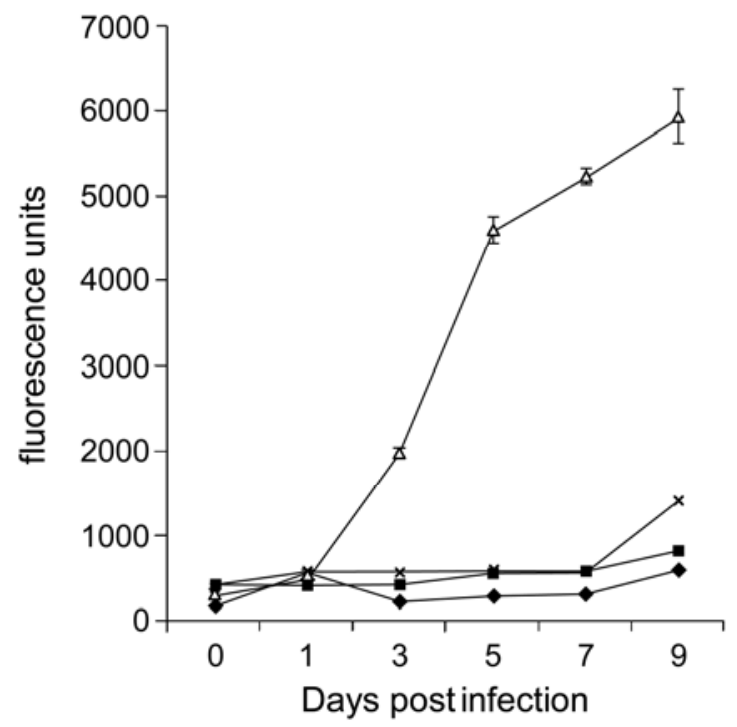

Fig. 7. Application of the wheat germ agglutinin chitin assay to measure Erysiphe necator infection of grapevine (Vitis vinifera). A time course of $E$. necator growth on leaves of the susceptible $V$. vinifera genotype 'Cabernet Sauvignon' (white triangles) and the resistant grapevine genotype BC5:3294-R23 (black X). Uninfected control tissues of each genotype are shown as black diamonds and black squares, respectively. Each data point is the average of four technical replicates, each containing $20 \mathrm{mg}$ of homogenate derived from two grapevine leaves. Standard errors are indicated for each measurement. 
An essential prerequisite of the WAC assay is a relatively uniform inoculation of plant material. This requirement is not unique to this assay and the quantitative analysis of any in planta fungal growth requires similar inoculation uniformity, as does the qualitative assessment of disease resistance in most cases. Variation due to differential inoculation can be largely circumvented by replication of treatments and pooling of replicated material, a process the WAC assay greatly lends itself to because large volumes of tissue can be homogenized together. The ability of the WAC assay to distinguish germplasm infected under less controlled field conditions confirms the relevance of this method under agricultural situations. Even though significantly different levels of fungal growth were observed between Thatcher and Thatcher M1 and M2 lines under field conditions, presumably due to variation in natural infection levels, these samples all strongly adhered to the same trend compared with resistant lines. Such variation could presumably be further reduced by additional sampling.

Surprisingly, the application of the WAC assay to Arabidopsis is complicated by an apparently age-dependent increase in background fluorescence. Although the WAC assay could still be applied to this species, this added complication makes the assay less attractive. The Arabidopsis finding further suggests that it is advisable to undertake a thorough microscopic analysis of pathogen-infected tissues and homogenates when establishing the WAC assay in untested pathosystems. WAC homogenates from mildew-infected grapevine leaves were shown to contain small fungal fragments not associated with plant tissue and likely to be lost without centrifugation, again demonstrating the value of microscopy of homogenates when dealing with new pathosystems. This microscopy, however, is straightforward because the WAC assay is based upon a simple microscopic technique.

In summary, the WAC assay is applicable to monocotyledonous and dicotyledonous crop species, such as wheat and grapevine, and provides effective quantification of several different fungal pathogen species. Because chitin is a basic cell wall component of many fungal species, this assay will be applicable to many other pathosystems. However, the WAC assay is not a substitute for an experienced plant pathologist's eye, which can add further description to disease status based upon disease phenotype and plant symptoms. An experienced pathologist can also rapidly score large numbers of plants visually using a qualitative scale such as the Stakman rust scoring system (Stakman et al. 1962) in the field, which will obviously be faster than a quantitative analysis and has proven sufficient for most breeding purposes. However, in those situations were an accurate, sensitive, simple, and nonsubjective measurement of fungal growth is required, it will serve as a valuable tool for plant pathology studies.

\section{MATERIALS AND METHODS}

Pathogen infection of wheat seedlings.

Wheat seedlings were infected with $P$. graminis f. sp. tritici spores as previously described (Ayliffe et al. 2004), while powdery mildew (B. graminis f. sp. tritici) infection occurred by natural infection of glasshouse material.

Field comparison of $\mathrm{Lr} 46 / \mathrm{Yr} 29$ and $\mathrm{Lr} 34 / \mathrm{Yr} 18$ wheat lines.

An F2 family was produced from a cross between two Avocet-derived lines that carried $\mathrm{Lr} 46 / \mathrm{Yr} 29$ and $\mathrm{Lr} 34 / \mathrm{Yr} 18$, respectively. From the resultant F2 progeny, molecular markers (Lagudah et al. 2009) were used to identify plants that were homozygous for Lr46/Yr29, Lr34/Yr18, Lr46/Yr29, and Lr34/Yr18 or null for both genes. Ten homozygous lines were identified for each genotype and 50 seeds from each line planted in randomized field plots. Interspaced among these plants were mixed plots of three rust-susceptible wheat cultivars-'Morocco', Sonora, and 'Nyabing'—which served as a source of rust inoculum throughout the growing season. These mixed susceptible plots were infected at the mid-vegetative stage with $P$. striiformis and $P$. triticina, allowing increasing levels of rust inoculum to infect the adjacent Avocet-derived material throughout the growing season. Five flag leaves were randomly collected from each plot after completion of grain filling and subsequently processed by the WAC assay.

\section{Field comparison}

\section{of Thatcher $\mathrm{Lr34/Yr18}$ and $\mathrm{Lr67} / \mathrm{Yr} 46$ wheat lines.}

Thatcher wheat and near-isogenic derivatives with the Lr34/Yrl8 gene (Thatcher*6/PI58548) and Lr67/Yr46 gene (Thatcher*6/PI250413) were sown in field plots with approximately 50 seeds per meter of row. Included among this germplasm were three EMS mutagenized (M3 generation) lines of Thatcher Lr67/Yr46, two of which had each independently lost rust resistance while the third line maintained the Lr67/Yr46 phenotype. Rust inoculum development in the field was as described with the spreader rows in the Avocet Lr46/Yr29 and Lr34/Yr18 studies. Flag leaves were randomly sampled from five plants from each of the Thatcher-derived lines for the WAC assay.

\section{Infection of grapevine genotypes with $E$. necator.}

$E$. necator was maintained on detached leaves of $V$. vinifera Cabernet Sauvignon using an 8- to 10-day rotation, as previously described (Donald et al. 2002). Young surface-sterilized leaves from greenhouse-grown V. vinifera Cabernet Sauvignon (susceptible) and BC5:3294-R23 vines (which contain the RUN1 locus introgressed from Muscadinia rotundifolia into $V$. vinifera) (Donald et al. 2002) were infected evenly by touch with a sporulating powdery-mildew-infected leaf. Plates were incubated at $25^{\circ} \mathrm{C}$ under a 12-h light-and-dark cycle and tissue collected at $0,1,3,5,7$, and $9 \mathrm{dpi}$.

\section{Quantification of fungal biomass by chitin measurement.}

Plant leaf tissue was harvested, weighed, cut into $3-\mathrm{cm}$ lengths, and placed into 50-ml Falcon tubes. Sufficient volume of $1 \mathrm{M} \mathrm{KOH}$ containing $0.1 \%$ (vol/vol) Silwet L-77 (Lehle Seeds, Round Rock, TX, U.S.A.) was added to each tube to entirely cover the tissue. Tissues were then autoclaved using a standard sterilization cycle $\left(121^{\circ} \mathrm{C}\right.$ and 15 psi for $\left.20 \mathrm{~min}\right)$. After autoclaving, the tissue was briefly washed with $50 \mathrm{ml}$ of 50 $\mathrm{mM}$ Tris, $\mathrm{pH} 7.0$, then resuspended in a second 50-ml volume of $50 \mathrm{mM}$ Tris, $\mathrm{pH} 7.0$ (note that the tissue is fragile at this stage). Samples were allowed to neutralize for at least $15 \mathrm{~min}$ and the buffer solution replaced such that $1 \mathrm{ml}$ of Tris $(\mathrm{pH} 7.0)$ solution was present for each $200 \mathrm{mg}$ of plant tissue. The plant tissue was then macerated by either sonication or using a polytron blender to generate a fine, uniform suspension of tissue. Approximately $1 \mathrm{~min}$ of sonication or blending was usually sufficient to produce a uniform suspension although, in the case of Arabidopsis, additional hand grinding with a mortar and pestle was necessary to break up the fibrous root and stem material. A sample (usually 100 to $200 \mu \mathrm{l}$ ) of each tissue suspension was added to a $200-\mu \mathrm{l}$ PCR tube containing $10 \mu \mathrm{l}$ of a $1-\mathrm{mg} / \mathrm{ml}$ solution of WGA-FITC (Sigma Aldrich) dissolved in water. The ends of pipette tips were removed prior to all sample pipetting and homogenates were regularly agitated to ensure that a uniform sample was collected. The sample and stain solution were briefly mixed by repetitive pipetting and left to stand for at least $10 \mathrm{~min}$ at room temperature. Note that increased staining times can lead to increased fluorescence; therefore, it is essential that samples to be directly compared 
are processed together. Between three to six replicate samples were used for each tissue preparation and strips of 12 PCR tubes were used for ease of sample handling. Following staining, samples were centrifuged at $600 \times g$ for $3 \mathrm{~min}$. The supernatant containing unbound stain was removed by pipetting and the pellet resuspended in $200 \mu \mathrm{l}$ of $50 \mathrm{mM}$ Tris, pH 7.0. Samples were washed three times in $200 \mu \mathrm{l}$ of $50 \mathrm{mM}$ Tris $(\mathrm{pH}$ 7.0), resuspended in $100 \mu \mathrm{l}$ of $50 \mathrm{mM}$ Tris ( $\mathrm{pH} 7.0$ ), and transferred to black, 96-well microtiter trays for fluorometry. Fluorometric measurements were made with a Wallac Victor 1420 multilabel counter (Perkin-Elmer Life Science, Waltham, MA, U.S.A.) fluorometer with 485-nm adsorption and 535-nm emission wavelengths and a 1.0-s measurement time.

\section{Production of a chitin standard curve.}

Homogenate from uninfected control plant tissue was spiked with ground-up, purified crab shell chitin particles (Sigma Aldrich) to generate a standard curve.

\section{Microscopic analysis of samples and subsequent chitin quantification.}

Fungus-infected plant tissues were processed for microscopy as described by Ayliffe and associates (2011). Briefly, tissue was harvested and autoclaved in $1 \mathrm{M} \mathrm{KOH}$ and then neutralized in $50 \mathrm{mM}$ Tris, $\mathrm{pH}$ 7.0. Following neutralization, tissue samples were stained with $20 \mu \mathrm{g}$ of WGA-FITC, rinsed in water, then subjected to microscopy under blue-light excitation. After microscopy, samples were homogenized and then processed by the WAC assay.

\section{ACKNOWLEDGMENTS}

We thank the Australian Grains Research and Development Corporation for financial support, M. Soliveres and S. Chakraborti for technical support, and the Plant Breeding Institute, University of Sydney for field site access.

\section{LITERATURE CITED}

Ahn, S. W., and Ou, S. H. 1982. Quantitative resistance of rice to blast disease. Phytopathology 72:279-282.

Allen, A. K., Neuberger, A., and Sharon, N. 1973. The purification, composition and specificity of wheat germ agglutinin. J. Biochem. 131:155-162.

Ayliffe, M. A., Steinau, M., Park, R. F., Rooke, L., Pacheco, M. G., Hulbert, S. H., Trick, H. N, and Pryor, A. J. 2004. Aberrant mRNA processing of the maize $R p 1-D$ rust resistance gene in wheat and barley. Mol. PlantMicrobe Interact. 17:853-864.

Ayliffe, M. A., Singh, R., and Lagudah, E. S. 2008. Durable resistance to stem rust needed. Curr. Opin. Plant Biol. 11:187-192.

Ayliffe, M. A, Devilla, R., Mago, R., White, R., Talbot, M., Pryor, A., and Leung, H. 2011. Non-host resistance of rice to rust pathogens. Mol. Plant-Microbe Interact. 24:1143-1155.

Bani, M., Rubiales, D., and Rispail, N. 2012. A detailed evaluation method to identify sources of quantitative resistance to Fusarium oxysporum f. sp. pisi race 2 within a Pisum spp. germplasm collection Plant Pathol. 61:532-542.

Bao, J. R., Velemaa, J., and Dobinson, K. F. 2000. Using GUS expression in a nonpathogenic Fusarium oxysporum strain to measure fungal biomass. Can. J. Plant Pathol. 24:340-348.

Bhavanandan, V. P., and Katlic, A. W. 1979. The interaction of wheat germ agglutinin with sialoglycoproteins. J. Biol. Chem. 254:4000-4008.

Bock, C. H., Gottwald, T. R., Parker, P. E., Ferrandino, F., Welham, S., van den Bosch, F., and Parnell, S. 2010. Some consequences of using the Horsfall-Barratt scale for hypothesis testing. Phytopathology 100:10301041.

Chen, N., Hsiang, T., and Goodwin, P. H. 2003. Use of a green fluorescent protein to quantify the growth of Colletotrichum during infection of tobacco. J. Microbiol. Methods 53:113-122.

Chong, J., Harder, D. E., and Rohringer, R. 1985. Cytochemical studies on Puccinia graminis f. sp. tritici in a compatible wheat host. I. Walls of intercellular hyphal cells and haustorium mother cells. Can. J. Bot. 63:1713-1724.

Delgado, N. J., Casler, M. D., Grau, C. R., and Jung, H. G. 2002. Reactions of smooth bromegrass clones with divergent lignin or etherified ferulic acid concentration to three fungal pathogens. Crop Sci. 42:18241831.

Diener, A. 2012. Visualizing and quantifying Fusarium oxysporum in the plant host. Mol. Plant-Microbe Interact. 25:1531-1541.

Diener, A. C, and Ausubel, F. M. 2005. RESISTANCE TO FUSARIUM OXYSPORUM 1, a dominant Arabidopsis disease-resistance gene, is not race specific. Genetics 171:305-321.

Donald, T. M., Pellerone, F., Adam-Blondon, A.-F., Bouquet, A., Thomas, M. R., and Dry, I. B. 2002. Identification of resistance gene analogs linked to a powdery mildew resistance locus in grapevine. Theor. Appl. Genet. 104:610-618.

El Gueddari, N. E., Ruachhaus, U., Moerschbacher, B. M., and Deising, H. B. 2002. Developmentally regulated conversion of surface-exposed chitin to chitosan in cell walls of plant pathogenic fungi. New Phytol. 156:103-112.

El-Nashaar, H. M., Moore, K. W., and George, R. A. 1986. Enzyme-linked immunosorbent assay quantification of initial infection of wheat by Gaeumannomyces graminis var. tritici as moderated by biocontrol agents. Phytopathology 76:1319-1322.

Fisher, M. C., Henk, D. A., Briggs, C. J., Brownstein, J. S., Madoff, L. C., McCraw, S. L., and Gurr, S. L. 2012. Emerging fungal threats to animal, plant and ecosystem health. Nature 484:186-194.

Gassner, G., and Starib, W. 1932. Die bestimmung der biologischen rassen de weizengelbrostes (Puccinia glumarum f. sp. tritici (Schmidt.) Erikss.undHenn.) Arb. Biol. Reichsanst. Land Forstwirtsch. Berlin Dahlem 20:141-163.

Goodwin, P. H., and Hsiang, T. 2010. Quantification of fungal infection of leaves with digital images and scion image software. Methods Mol. Biol. 638:125-135.

Harrison, J. G., Barker, H., Lowe, R., and Rees, E. A. 1990. Estimation of amounts of Phytophthora infestans mycelium in leaf tissue by enzymelinked immunosorbent assay. Plant Pathol. 39:274-277.

Hisamatsu, M., and Yamada, T. 1989. Partially deacetylated chitin as an acid-stable support for enzyme immobilization. J. Ferment. Bioeng. 67:219-220.

Hogg, A. C., Johnston, R. H., and Dyer, A. T. 2007. Applying real-time quantitative PCR to Fusarium crown rot of wheat. Plant Dis. 91:10211028.

Horsfall J. G., and Barratt, R. W. 1945. An improved grading system for measuring plant disease. (Abstr.) Phytopathology 35:655.

Jafary, H, Szabo, L. J., and Niks, R. E. 2006. Innate nonhost immunity in barley to different heterologous rust fungi is controlled by sets of resistance genes with different and overlapping specificities. Mol. Plant-Microbe Interact. 19:1270-1279.

Kamoun, S., van West, P., and Gover, F. 1998. Quantification of late blight resistance of potato using transgenic Phytophthora infestans expressing B-glucuronidase. Eur. J. Plant Pathol. 104:521-525.

Klosterman, S. J. 2012. Real-time PCR for quantification of fungi in planta. Methods Mol. Biol. 835:121-132.

Lagudah, E. S., Krattinger, S. G., Herrera-Foessel, S., Singh R. P., HuertaEspino, J., Spielmeyer, W., Brown-Guedira, G., Selter, L. L., and Keller, B. 2009. Gene-specific markers for the wheat gene Lr34/Yr18/Pm38 which confers resistance to multiple fungal pathogens. Theor. Appl. Genet. 119:889-898.

Larsen, R. C., Vandemark, G. J., and Grau, C. R. 2007. Development of a real-time polymerase chain reaction assay for quantifying Verticillium albo-atrum DNA in resistant and susceptible alfalfa. Phytopathology 97:1519-1525.

Lievens, B., Brouwer, M., Vanachter, A. C. R. C., Cammune, B. P. A., and Thomma, B. P. H. J. 2006. Real-time PCR for detection and quantification of fungal and oomycete tomato pathogens in plant and soil samples. Plant Sci. 171:155-166.

Lillemo, M., Singh, R. P., William, M., Herrera-Foessel, S., HuertaEspino, J., German, S., Campos P., Xia, X. C., and Lagudah, E. 2011. Multiple rust resistance and gene additivity in wheat: Lessons from multi-location case studies in cultivars Parula and Saar. Pages 111-120 in: Proceedings Borlaug Global Rust Initiative 2011 Technical Workshop, June 13-16, Saint Paul, Minnesota, U.S.A. Borlaug Global Rust Initiative, Ithaca, NY, U.S.A.

McNeal, F. H, Konzak, C. F., Smith, E. P., Tate, W. S., and Russell, T. S. 1971. A uniform system for recording and processing cereal research data. Agric. Res. Serv. Bull. 34-121. United States Department of Agriculture, Washington, DC.

Meyberg, M. 1988. Selective staining of fungal hyphae in parasitic and symbiotic plant-fungus associations. Histochemistry 88:197-199.

Nicholson P., Simpson, D. R., Weston, G., Rezanoor, H. N., Lees, A. K., Parry, D. W., and Joyce, D. 1998. Detection and quantification of Fusarium culmorum and Fusarium graminaearum in cereals using PCR assays. Physiol. Mol. Plant Pathol. 53:17-37.

No, H. K., and Meyers, S. P. 1995. Preparation and characterisation of chi- 
tin and chitosan. J. Aquat. Food Prod. Technol. 4:27-51.

O'Connell, R. J., and Ride, J. P. 1990. Chemical detection and ultrastructural localisation of chitin in cells walls of Colletotrichum lindemuthianum. Physiol. Mol. Plant Pathol. 37:39-53.

Papadopoulou, K. K., Kavroulakis, N., Tourn, M., and Aggelou, I. 2005. Use of B-glucuronidase activity to quantify the growth of Fusarium oxysporum f. sp. radicis-lycopersici during infection of tomato. J. Phytopathol. 153:325-332.

Pariaud, B., Robert, C., Goyeau, H., and Lannou, C. 2009. Aggressiveness components and adaptation to a host cultivar in wheat leaf rust. Phytopathology 99:869-878.

Roth, J. 1978. The biological functions of the lectins, 2. Wheat germ agglutinin. Pages 21-23 in: The Lectins: Molecular Probes in Cell Biology and Membrane Research. J. Roth, ed. VEB Gustav Fischer Verlag, Jena, Germany.

Seiffert, U., and Schweizer, P. 2005. A pattern recognition tool for quantitative analysis of in planta hyphal growth of powdery mildew fungi. Mol. Plant-Microbe Interact. 18:906-912.
Silvar, C., Diaz, J., and Merino, F. 2005. Real-time polymerase chain reaction quantification of Phytophthora capsici in different pepper genotypes. Phytopathology 95:1423-1429.

Stakman, E. C., Stewart, D. M, and Loegering, W. Q. 1962. Identification of physiologic races of Puccinia graminis var. tritici. Agric. Res. Serv. E617. United States Department of Agriculture, Washington, DC.

Strange, R. N. 2005. Plant disease: A threat to global food security. Annu. Rev. Phytopathol. 43:83-116.

Walker, S. J., and Bosland, P. W. 1999. Inheritance of Phytophthora root rot and foliar blight resistance in pepper. J. Am. Hortic. Sci. 124:14 18.

Wijekoon, C. P., Goodwin, P. H., and Hsiang, T. 2008. Quantifying fungal infection of plant leaves by digital image analysis using Scion Image software. J. Microbiol. Methods 74:94-101.

Wilhem, S., Sagen, J. E., and Tietz, H. 1974. Resistance to Verticillium wilt in cotton: Sources, techniques of identification, inheritance trends and the resistance potential of multiline cultivars. Phytopathology 64:924-931. 